\title{
The Effect of Labor on Neonatal T-Cell Phenotype and Function
}

\author{
CATHERINE A. THORNTON, CARLO C. CAPRISTO, LYNSEY L. POWER, \\ JUDITH A. HOLLOWAY, ELEANOR J. POPPLEWELL, NORMA D. DIAPER, AND \\ JOHN O. WARNER \\ Infection, Inflammation and Repair, School of Medicine, University of Southampton, U.K.
}

\begin{abstract}
With increasing interest in the role of fetal programing in child and adulthood diseases, and therefore interest in the measurement of various factors at birth, it is essential to ascertain whether the factors of interest show any gestation- or parturitionassociated changes. We have investigated whether mode of delivery influenced T-cell phenotype and function $\left(\mathrm{CD}^{+}\right)$as has been described for monocytes and neutrophils. Interferon- $\gamma$ production in response to either the mitogen phytohemagglutinin or anti-CD2/CD3/CD28 F(ab') $)_{3}$ was significantly reduced by neonatal mononuclear cells compared with adult cells but did not differ with mode of delivery at term (normal vaginal delivery versus elective lower-segment cesarean section). Likewise, antiCD2/CD3/CD28-stimulated IL-2 production by the neonate was lower than adult levels but did not differ with mode of delivery. The expression of common T-cell activation markers (CD25, MHC class II, CD69, CD62L, CD11a, CD44, and CD49d) was examined. Only CD62L (L-selectin) expression was significantly different, with fewer adult $\mathrm{T}$ cells expressing this surface antigen compared with neonatal $\mathrm{T}$ cells $(p<0.0003)$, and significantly more $\mathrm{T}$ cells from lower-segment cesarean section than normal vaginal delivery were positive for CD62L $(p=0.012)$. $\mathrm{sCD} 62 \mathrm{~L}$ levels were significantly lower in cord plasma compared with
\end{abstract}

\section{ABSTRACT}

adult plasma but did not differ with mode of delivery. Thus the phenotype and function of cord blood $\mathrm{T}$ cells did not differ greatly with mode of delivery, but possible differences for the marker of interest should always be assessed. Furthermore, although there was no significant difference with mode of delivery for all markers, except CD62L, the variation in the normal vaginal delivery samples, as for the adults, was greater than in the lower-segment cesarean section samples, indicating that the effects of length of labor and stress at delivery may well be relevant. (Pediatr Res 54: 120-124, 2003)
Abbreviations
sCD62L, soluble CD62L (L-selectin)
MFI, mean fluorescence intensity
NVD, normal vaginal delivery
LSCS, lower-segment cesarean section
PHA, phytohemagglutinin
CBMC, cord blood mononuclear cells
TCR, T-cell receptor
IFN- $\boldsymbol{\gamma}$, interferon- $\gamma$
R-PE, Phycoerythrin

Numerous investigators use the analysis of umbilical CBMC as a means of assessing immunologic status of the newborn. Recently, there has been a great deal of interest in the identification of markers detectable at birth that can predict subsequent disease development by the child or adult of, for example, atopic diseases such as eczema, hayfever, and asthma (1). The methodologies used in such analyses include assessment of cellular function by cell culture, phenotype by flow cytometry, and the measurement of various immunologic mediators in the circulation by ELISA. However, the influence mode of

Received November 28, 2001; accepted October 22, 2002.

Correspondence: Catherine Thornton, Ph.D., Allergy and Inflammation Sciences, Level G Mailpoint 803, Southampton General Hospital, Southampton, SO16 6YD, UK; e-mail: caj@soton.ac.uk

Supported by the National Institutes of Health (grant number HL61858).

DOI: 10.1203/01.PDR.0000069704.25043.BA delivery might have on many of the markers of interest is largely unstudied.

Labor is associated with an increase in the number of leukocytes in the neonate's circulation typically related to increased neutrophils, monocytes, and natural killer cells (25). Functional differences have also been observed, including increased IL-6 production by umbilical cord blood monocytes (5) and activation of neutrophils (6) collected after spontaneous vaginal delivery (completion of labor) compared with elective cesarean section (no labor). Furthermore, length of or amount of stress during labor caused progressively increasing activation of neutrophils (6) and leukocytosis (7), respectively.

The labor-associated activation of the fetal immune system is postulated to reflect increased prostanoid and proinflammatory cytokine production in the uterine environment (8). However, there is also a cortisol surge that occurs in conjunction with labor, leading to increased cortisol levels in umbilical 
cord blood samples from neonates delivered by spontaneous vaginal delivery (9). Cortisol is an immunosuppressive molecule, inhibiting cytokine production and, thereby, T-cell effector function $(10,11)$. As glucocorticoids inhibit early signaling events after TCR stimulation, including tyrosine phosphorylation (12), T-cell function may be particularly susceptible to the effects of labor. Therefore, we undertook an analysis of the phenotype and function of umbilical CBMC, focusing on $\mathrm{CD}^{+}{ }^{+} \mathrm{T}$ cells because of their important role as effector cells and their ability to provide help to other hematopoietic populations, obtained from newborns delivered after spontaneous labor (NVD) in comparison to cells prepared from samples obtained from infants delivered in the absence of labor (elective LSCS).

\section{METHODS}

Blood samples. Umbilical cord blood was collected by venepuncture of the umbilical cord immediately on delivery of the placenta. Umbilical cord blood was collected from fullterm, healthy, singleton newborns after 1$)$ elective LSCS $(n=$ 13) for breech presentation, cephalopelvic disproportion, previous section, or self-selected section (women with a clinical indication for having an elective cesarean section were excluded from the study); or 2) NVD initiated spontaneously ( $n$ $=14$ ) from subjects who did not have a history of gestationassociated diseases, such as preeclampsia, or placental abruption. The presence of intrauterine infection was not assessed. Adult blood was collected from healthy volunteers $(n=14)$. All samples were collected into lithium heparin (Vacutainer; BD Biosciences, Oxford, UK) and processed within $2 \mathrm{~h}$ of collection. Informed consent was obtained from the donors, and the Southampton and S.W. Hants Joint Research Ethics Committee approved the study.

Flow cytometry. Whole blood $(50 \mu \mathrm{L})$ was placed in a tube with a preoptimized concentration of fluorochrome-conjugated antibodies and incubated in the dark and on ice for $30 \mathrm{~min}$. Red blood cell lysis was conducted by the addition of $2 \mathrm{ml}$ of $1 \times$ FACS Lysing Solution (BD) and incubation at room temperature for $12 \mathrm{~min}$. After centrifugation at $400 \times \mathrm{g}, 4^{\circ} \mathrm{C}, 7 \mathrm{~min}$, the pellet was washed twice by centrifugation with $3 \mathrm{ml}$ of $\mathrm{PBS} / 0.5 \%$ BSA $/ 0.2 \%$ sodium azide. The pellet was resuspended in $100 \mu \mathrm{L}$ of $1 \%$ formalin in PBS and stored in the dark at $4^{\circ} \mathrm{C}$ until acquisition by flow cytometry (FACScan; BD) within $2 \mathrm{~d}$ of staining. The population identified by characteristic side scatter and CD4-positivity was acquired $(10,000$ events, with total events collected and saved) for analysis using CellQuest software (BD). The antibodies (all from PharMingen) used for flow cytometry were FITC-conjugated anti-CD4 (mIgG1, clone RPA-T4), and the following R-PE-conjugated antibodies; anti-CD11a (mIgG1, clone HI111), anti-CD25 (mIgG1, clone M-A251), anti-CD44 (mIgG2b, clone G44-26), anti-CD49d (mIgG1, 9F10), and anti-CD62L (mIgG1, clone Dreg 56). Isotype controls (mIgG1, clone MOPC-21; mIgG2b, clone 27-35) were included as appropriate.

Mononuclear cell culture. Mononuclear cells were prepared from heparinized umbilical cord and adult peripheral blood by centrifugation over Histopaque (Sigma Chemical Co, Poole,
U.K.). Cells at the interface were collected and washed twice in RPMI 1640 with Glutamax (GIBCO Life Technologies), and then cells were cultured at $10^{6} / \mathrm{mL}$ in RPMI 1640 with Glutamax supplemented with $5 \% \mathrm{AB}$ serum (BioWhittaker), 100 $\mathrm{U} / \mathrm{mL}$ penicillin, $100 \mu \mathrm{g} / \mathrm{mL}$ streptomycin, and 2-mercaptoethanol $\left(2 \times 10^{-5} \mathrm{M}\right)$. Various stimuli were added at the initiation of culture: PHA $(1 \mu \mathrm{g} / \mathrm{mL})$ and $\mathrm{F}\left(\mathrm{ab}^{\prime}\right)_{3}$ anti-CD2/3/28 $(50 \mathrm{ng} / \mathrm{mL}$; a kind gift of Professor Martin Glennie, Cancer Sciences, School of Medicine, University of Southampton, U.K.). Cell-free culture supernatants were harvested after $24 \mathrm{~h}$ of incubation at $37^{\circ} \mathrm{C}$ in $5 \% \mathrm{CO}_{2}$ in air. Supernatants were stored at $-80^{\circ} \mathrm{C}$ until analysis.

\section{ELISA}

IFN- $\gamma$ and IL-2 were measured using OptEIA ELISA kits according to the manufacturer's instructions (PharMingen). The sensitivity of each assay was $5 \mathrm{pg} / \mathrm{mL}$. sCD62L was measured using a specific kit (Quantikine, R \& D Systems) with a sensitivity of $0.3 \mathrm{ng} / \mathrm{mL}$, and samples were diluted 1 in 10 in the sample buffer provided.

\section{STATISTICAL ANALYSIS}

Differences between the groups were assessed nonparametrically using Mann-Whitney $U$ test or Wilcoxon rank sum test (StatView, version 5.0).

\section{RESULTS}

Effect of mode of delivery on cytokine production. The stimulus used to assess neonatal T-cell function was a bioengineered $\mathrm{F}\left(\mathrm{ab} \mathrm{b}_{3}\right)_{3}$ molecule containing a single $\mathrm{Fab}$ ' fragment each of anti-CD2, anti-CD3, and anti-CD28. This is the in vitro stimulus that best resembles the physiologic interaction between $\mathrm{T}$ cells and antigen-presenting cells. The dose of anti$\mathrm{CD} 2 / 3 / 28$ used in the current investigation $(50 \mathrm{ng} / \mathrm{mL})$ was optimized in preliminary experiments. Initially, IFN- $\gamma$ production in response to this $\left.\mathrm{F}(\mathrm{ab})_{3}\right)_{3}$ molecule was compared with the frequently studied mitogen PHA. CBMC had reduced IFN- $\gamma$ production compared with adult cells irrespective of the stimulus used. There was no difference between CBMC collected from either spontaneous NVD or elective LSCS (Fig. 1A). IL-2 production by $\mathrm{CBMC}$ stimulated with anti-CD2/CD3/CD28 stimulation was also reduced compared with the adult, but there was no difference associated with mode of delivery (Fig. 1B). PHA-stimulated IFN- $\gamma$ production by adult mononuclear cells was significantly lower than that induced by anti-CD2/ $3 / 28$ ( $p=0.019$; Wilcoxon rank sum test).

Effect of mode of delivery on $\mathrm{CD}^{+} \mathrm{T}$ cell phenotype. The expression of numerous activation markers by $\mathrm{CD}^{+}{ }^{+} \mathrm{T}$ cells was examined. $\mathrm{CD}^{+} \mathrm{T}$ cells were identified by characteristic side scatter and CD4 positivity. Events $(10,000)$ within this gate were acquired and analyzed. The percentage of $\mathrm{CD}^{+} \mathrm{T}$ cells expressing CD25 (Fig. 2A), CD69 (data not shown), MHC class II (data not shown), or CD49d (data not shown) did not differ significantly from the adult cells or with mode of delivery. The percentage of $\mathrm{C} 62 \mathrm{~L}^{+} / \mathrm{CD} 4^{+}$cells was significantly higher than the adult cells (median, 85.01\%; range, 


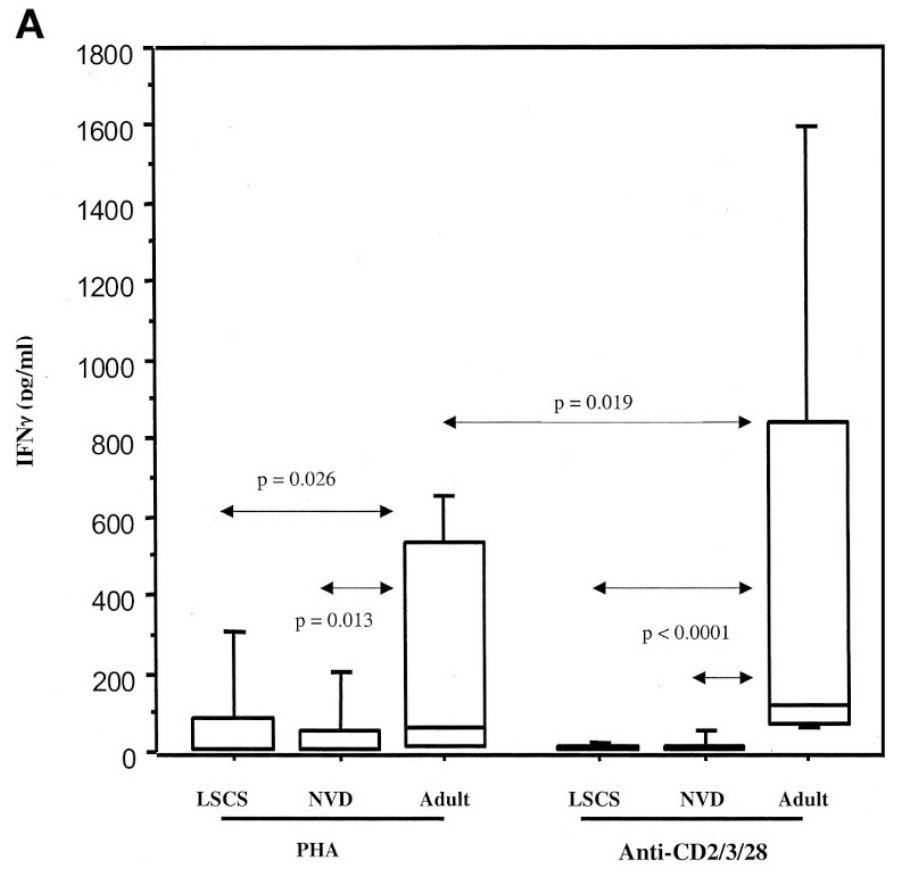

B

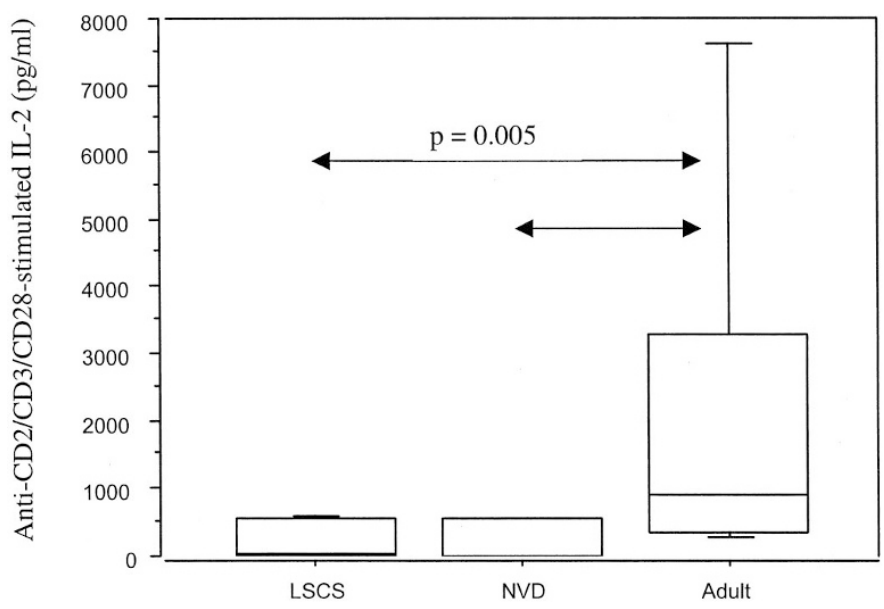

Figure 1. Cytokine production by neonatal mononuclear cells compared with adult mononuclear cells. Production of IFN- $\gamma$ in response to either PHA or anti-CD2/3/28 stimulation $(A)$ and of IL-2 in response to anti-CD2/3/28 $(B)$. Mononuclear cells prepared from cord blood after NVD or elective LSCS were compared with adult mononuclear cells.

$64.34-89.51 \%$ of $\mathrm{CD}^{+}{ }^{+} \mathrm{T}$ cells; $\left.n=14\right)$ for both modes of delivery ( $p=0.0002$ for LSCS and $p=0.0001$ for NVD) and also significantly higher in the LSCS group (median, $99.18 \%$; range, $98.70-99.42 \%$ of $\mathrm{CD}^{+}{ }^{+} \mathrm{T}$ cells; $n=13$ ) compared with the NVD group (median, 97.69\%; range, $92.31-99.29 \%$ of $\mathrm{CD}^{+} \mathrm{T}$ cells; $n=14 ; p=0.012$; Fig. $2 B$ ). As all CD4 ${ }^{+} \mathrm{T}$ cells expressed CD11a and CD44 the intensity of expression (MFI) was examined but did not differ significantly between any of the groups (Fig. 2, $C$ and $D$ ). However, like the adult cells, $\mathrm{CD} 4^{+} \mathrm{T}$ cells from umbilical cord blood collected after the completion of labor showed greater variability in the expression of these markers.

Effect of mode of delivery on soluble markers of immune function. Levels of SCD62L were significantly reduced in the neonatal compared with the adult circulation $(p<0.0001$ for both groups; Fig. 3) but there was no difference in plasma levels in association with the mode of delivery.

\section{DISCUSSION}

With increasing interest in development during fetal life and the etiology of disease in childhood and adult life, it is imperative that any differences in immunologic function, measurable at birth, but caused by gestation-associated events such as prematurity, parity, sex, intrauterine infection, and mode of delivery be accounted for. In the current study the effect of mode of delivery (with and without labor) on some basic immunologic functions and $\mathrm{CD}^{+} \mathrm{T}$-cell phenotype was investigated. $\mathrm{CD}^{+}{ }^{\mathrm{T}}$ cells were the focus as they are important effector cells and provide help to other hematopoietic populations.

This is the first study of CBMC to use the physiologic stimulus $\mathrm{F}\left(\mathrm{ab} \mathrm{b}^{\prime}\right)_{3}$ anti-CD2, CD3, and $\mathrm{CD} 28$, so it was essential to compare the effects of this molecule to a welldescribed response by neonatal cells. As mitogen-stimulated IFN- $\gamma$ production by CBMC is reduced compared with that from adult cells (13-15), we initially investigated the effect of mode of delivery on both PHA- and anti-CD2/3/28 induced IFN- $\gamma$ production. Reduced IFN- $\gamma$ production by neonatal cells was seen in response to both stimuli, and there was no difference associated with mode of delivery. Similarly IL-2 production in response to anti-CD2/3/28 did not differ with mode of delivery and was reduced compared with the adult, as already described in response to other stimuli.

Of the phenotypic analysis conducted on $\mathrm{CD} 4^{+} \mathrm{T}$ lymphocytes, the only statistically significant difference between cord blood and adult cells was the higher percentage of $\mathrm{CD}^{2} 2 \mathrm{~L}^{+} /$ $\mathrm{CD}^{+}$cells in the neonatal circulation. Furthermore, there were statistically significantly more $\mathrm{CD} 62 \mathrm{~L}^{+} / \mathrm{CD} 4^{+}$cells in the absence of labor (LSCS) compared with after the completion of labor (NVD). CD62L is shed from the surface of T cells during activation and migration across the vascular endothelium $(16,17)$, and our observation suggests that labor may have a slight activating effect on $\mathrm{T}$ lymphocytes or that some $\mathrm{CD} 4^{+}$ T-cell migration into the circulation occurs in association with labor. Further support for a slight $\mathrm{T}$ cell-activating effect of labor is provided by the increased variability in CD11a and CD44 MFI and percentage of CD25 ${ }^{+} \mathrm{T}$ cells in cord blood collected from NVD compared with LSCS samples. Adults also displayed a great variability in the expression of these activation markers.

The difference in the percentage of $\mathrm{CD} 62 \mathrm{~L}^{+}$cells with mode of delivery, and compared with the adult, prompted us to consider the levels of sCD62L in the circulation. Despite the significant differences in surface expression, there was no difference in SCD62L with mode of delivery, but levels in adult plasma were significantly higher than in umbilical cord blood plasma. The lack of difference in circulating levels of sCD62L with mode of delivery probably reflects the small, albeit significant, difference in surface levels in these two populations. As the shedding of CD62L by neutrophils is the greatest contributor to soluble levels it would 
A

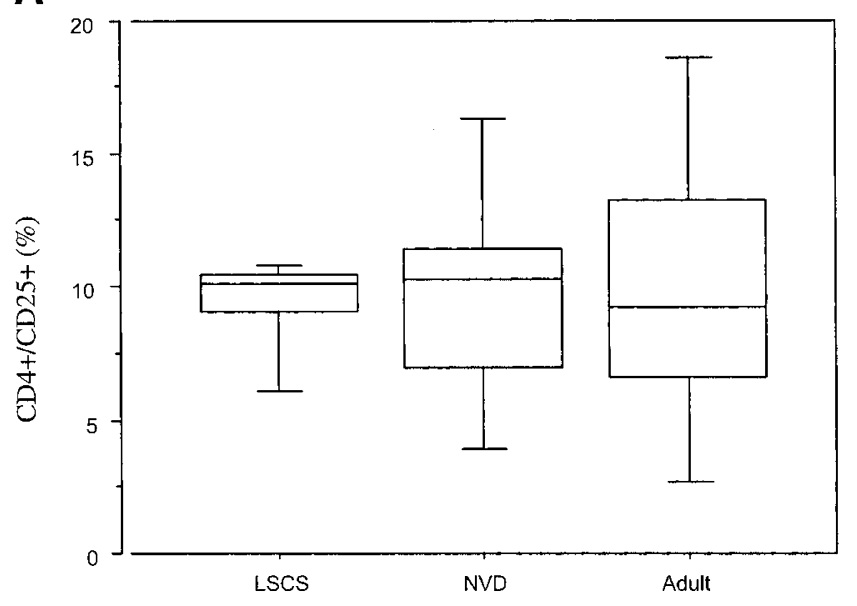

C

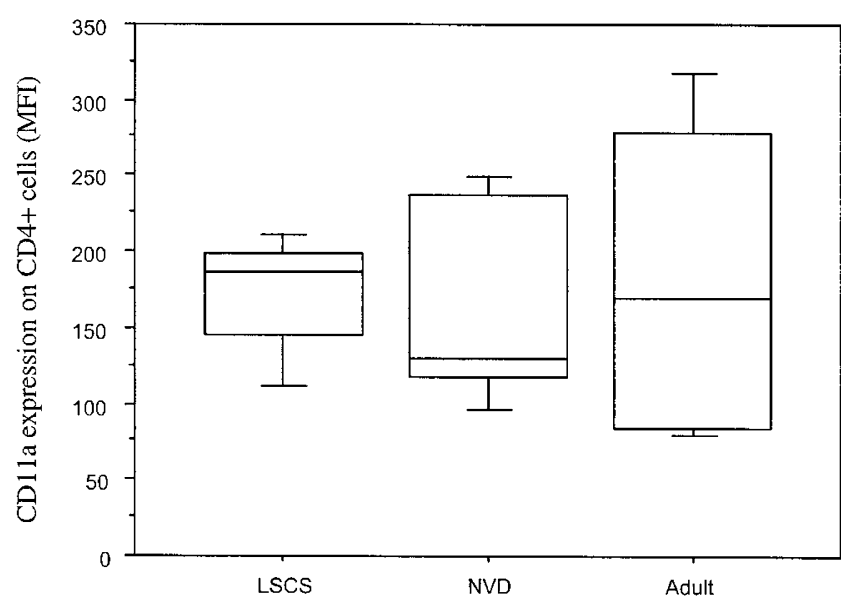

B

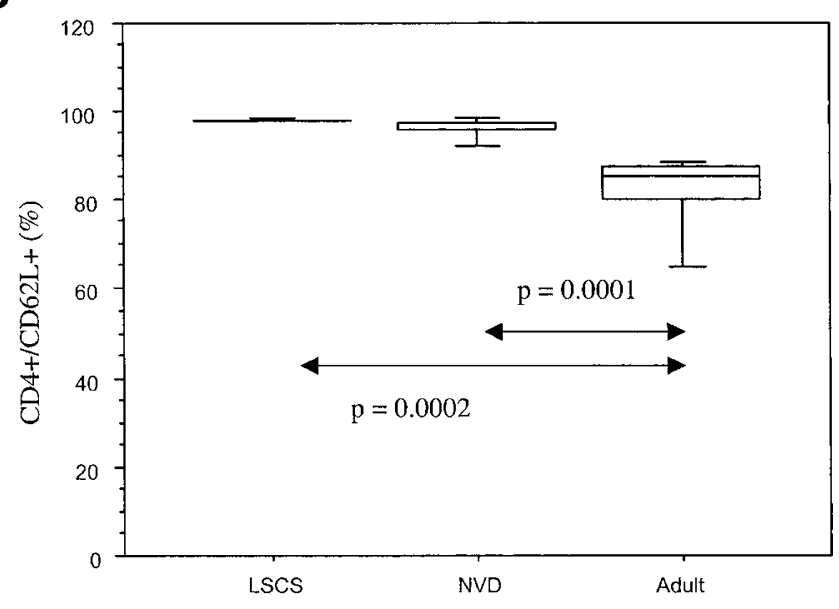

D

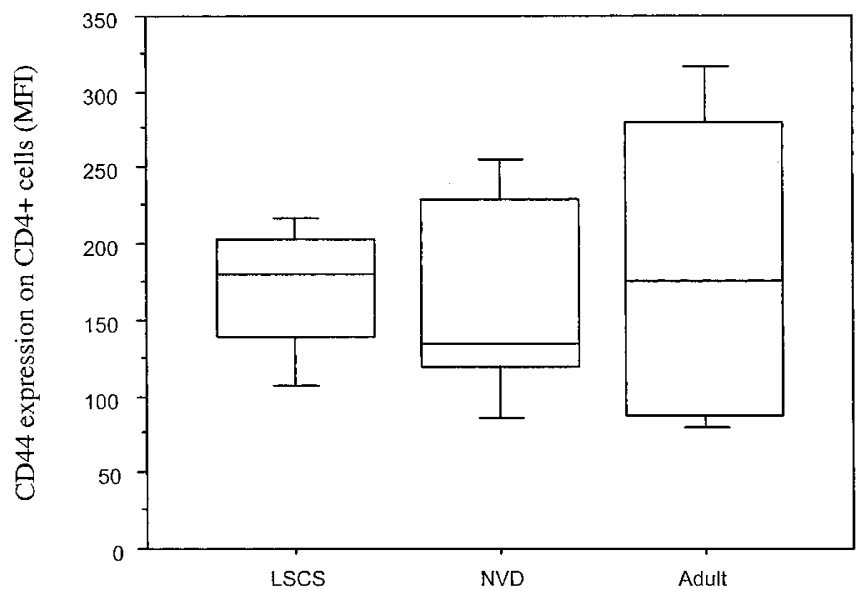

Figure 2. Expression of various surface molecules by $\mathrm{CD} 4^{+} \mathrm{T}$ cells from elective LSCS $v s$ NVD $v s$ adult. The percentage of $\mathrm{CD} 4^{+} \mathrm{T}$ cells expressing CD25 $(A)$ or CD62L $(B)$ and the level of expression (MFI) of CD11a $(C)$ or CD44 $(D)$ was examined.

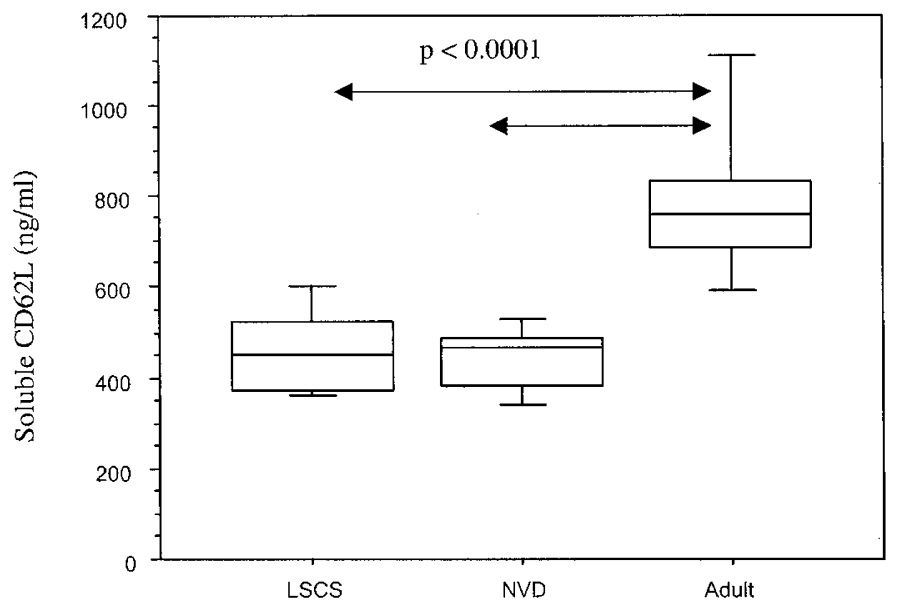

Figure 3. Levels of sCD62L in plasma from LSCS vs NVD vs adult were measured with a specific ELISA.

be interesting to examine the levels of membrane CD62L on neonatal neutrophils collected after different types of delivery and compare these to the adult. However, the accumulation of $\mathrm{sCD} 62 \mathrm{~L}$ in the circulation is associated with the shedding of CD62L by cells during extravasation from the circulation to the tissues $(17,18)$. Labor is associated with increased leukocytosis, so a lower percentage of cells expressing membrane CD62L might reflect those cells that have entered the circulation during labor. Such cells will have presumably shed $\mathrm{sCD} 62 \mathrm{~L}$ before entering the circulation; thus, plasma sCD62L may not change.

Unlike the marked changes in monocyte and neutrophil function that occur in association with human labor, T-cell function and phenotype, other than CD62L, does not change dramatically with labor. However, labor does appear to have a slight activating effect on $\mathrm{T}$ cells as shown by the reduced percentage of $\mathrm{CD}^{+}$cells expressing $\mathrm{CD} 62 \mathrm{~L}$ and the increased variability in expression of the surface markers we examined in the NVD samples. Thus it would be worthwhile to investigate the effects of labor length and stress in labor on T-cell phenotype and function. However, it is difficult to ascertain whether these changes in T-cell phenotype might actually be associated with the initiation of labor or whether they occur as a consequence of labor. As the effects of the mode of delivery may persist for many months postpartum (19), it is essential to understand the effect of this event on cellular phenotype and 
function (of not only $\mathrm{CD} 4^{+} \mathrm{T}$ cells) and relationships of these with subsequent outcomes, such as susceptibility to infection or atopy.

Acknowledgments. The authors thank the staff on the delivery suite at the Princess Anne Hospital, Southampton, for the collection of samples and all the mothers who participated in this study.

\section{REFERENCES}

1. Jones CA, Holloway JA, Warner JO 2000 Does atopic disease start in fetal life? Allergy 55:2-10

2. Gasparoni A, Maccario R, Chirico G, Belloni C, Mingrat G, De Amici D, Bonora MR, Rondini G 1992 Neonatal B lymphocyte subpopulations and method of delivery. Biol Neonate 61:137-141

3. Herson VC, Block C, Eisenfeld LI, Maderazo E, Krause PJ 1992 Effect of labor and delivery on neonatal polymorphonuclear leukocyte number and function. Am J Perinatol 9:285-288

4. Thilaganathan B, Meher-Homji N, Nicolaides KH 1994 Labor: an immunological beneficial process for the neonate. Am J Obstet Gynecol 171:1271-1272

5. Steinborn A, Sohn C, Sayehli C, Baudendistel A, Huwelmeier D, Solbach C, Schmitt E, Kauffman M 1999 Spontaneous labour at term is associated with fetal monocyte activation. Clin Exp Immunol 117:147-152

6. Weinschenk NP, Farina A, Bianchi DW 1998 Neonatal neutrophil activation is a function of labor length in preterm infants. Pediatr Res 44:942-945

7. Lim FTH, Scherjon SA, van Beckhoven JM, Brand A, Kanhai HH, Hermans JM, Falkenburg JH 2000 Association of stress during delivery with increased numbers of nucleated cells and hematopoietic progenitor cells in umbilical cord blood. Am J Obstet Gynecol 183:1144-1152

8. Kelly RW 1996 Inflammatory mediators and parturition. Rev Reprod 1:189-96

9. Ruth V, Hallman M, Laatikainen T 1993 Corticotropin-releasing hormone and cortisol in cord plasma in relation to gestational age, labor, and fetal distress. Am J Perinatol 10:115-118

10. Daynes RA, Araneo BA 1989 Contrasting effects of glucocorticoids on the capacity of T cells to produce the growth factors interleukin 2 and interleukin 4. Eur J Immunol 19:2319-2325

11. Ashwell JD, Lu FWM, Vacchio MS 1999 Glucocorticoids in T cell development and function. Annu Rev Immunol 18:309-345

12. van Laethem F, Baus E, Smyth LA, Andris F, Bex F, Urbain J, Kioussis D, Leo O 2001 Glucocorticoids attenuate T cell receptor signalling. J Exp Med 193:803-814

13. Lewis DB, Larsen A, Wilson CB 1986 Reduced interferon-gamma mRNA levels in human neonates. Evidence for intrinsic T cell deficiency independent of other genes involved in T cell activation. J Exp Med 163:1018-1023

14. Lewis DB, Yu CC, Meyer J, English BK, Kahn SJ, Wilson CB 1991 Cellular and molecular mechanisms for reduced interleukin 4 and interferon-gamma production by neonatal T cells. J Clin Invest 87:194-202

15. Vigano A, Esposito S, Arienti D, Zagliani A, Massironi E, Principi N, Clerici M 1999 Differential development of type 1 and type 2 cytokines and beta-chemokines in the ontogeny of healthy newborns. Biol Neonate 75:1-8

16. Berlin C, Bargatze RF, Campbell JJ, von Andrian UH, Szabo MC, Hasslen SR, Nelson RD, Berg EL, Erlandsen SL, Butcher EC $1995 \alpha$ Integrins mediate lymphocyte attachment and rolling under physiologic flow. Cell 80:413-422

17. Zimmerman GA, McIntyre TM, Prescott SM 1996 Adhesion and signalling in vasculature cell-cell interaction. J Clin Invest 98:1699-1702

18. Etzioni A 1996 Adhesion molecules: their role in health and disease. Pediatr Res 39:191-197

19. Gronlund M-M, Nuutila J, Pelto L, Lilius EM, Isolauri E, Salminen S, Kero P, Lehtonen OP 1999 Mode of delivery directs the phagocytic functions of infants for the first 6 months of life. Clin Exp Immunol 116:521-526 